\title{
EFFECT OF ZINC OXIDE NANOPARTICLES ON THE THERMAL, MECHANICAL AND WATER ABSORPTION PROPERTIES OF POLYLACTIC ACID/CHITOSAN COMPOSITES
}

\author{
Teuku Rihayat ${ }^{* 1}$ (D), Nurhanifa ${ }^{2}$, Tezara Cionita 3 四 \\ *1 Department of Chemical Engineering, Politeknik Negeri Lhokseumawe, Aceh, Indonesia \\ 2 Departement of Renewable Energy Engineering, Universitas Malikussaleh, Aceh, Indonesia \\ ${ }^{3}$ Department of Mechanical Engineering, Faculty of Engineering and Quantity Surveying, INTI \\ International University, 71800, Nilai, Negeri Sembilan, Malaysia
}

DOI: https://doi.org/10.29121/granthaalayah.v8.i12.2020.2457

Article Type: Research Article

Article Citation: Teuku Rihayat, Nurhanifa, and Tezara Cionita. (2020). EFFECT OF ZINC OXIDE NANOPARTICLES ON THE THERMAL, MECHANICAL AND WATER ABSORPTION PROPERTIES OF POLYLACTIC ACID/CHITOSAN COMPOSITES. International Journal of Research -GRANTHAALAYAH, 8(12), 15-23.

https://doi.org/10.29121/granthaa layah.v8.i12.2020.2457

Received Date: 17 November 2020

Accepted Date: 24 December 2020

\section{Keywords:}

Polylactic Acid

Zinc Oxide Nanoparticles

Chitosan

Composites

Polymers

\section{ABSTRACT}

The aim of this work is to improve the mechanical, thermal and water absorption properties of PLCHZ composites. The formation of the composites are mixing polylactic acid with zinc oxide nanoparticles ( $\mathrm{ZnO}$ ) and chitosan as filler. It produced through the precipitation method using a water bath under a temperature of $60 \mathrm{oC}$. Five prepared samples are pure PLA, PLCH, PLCHZa, PLCHZb and PLCHZc. The incorporating effect of fillers on the properties of samples is investigated in terms of mechanical, thermal and water absorbtion test. The result showed that mechanical and thermal properties increased with the addition of $\mathrm{ZnO}$ nanoparticles compared to pure PLA and PLCH. Nevertheless, those properties increased up to $2 \mathrm{wt} \%$ of $\mathrm{ZnO}$ nanoparticles loading but decreased when it content is increased up to $3 \mathrm{wt} \%$ and $4 \mathrm{wt} \%$. PLCHZa with the smallest content of 2 wt $\% \mathrm{ZnO}$ nanoparticles showed the highest value of $15 \mathrm{MPa}$ in tensile strength and $330.6 \mathrm{oC}$ in thermal resistant. In water absorbtion test, PLCHZc with $4 \mathrm{wt} \% \mathrm{ZnO}$ has better absorb ability as well as the lowest percentage absorption rate of $0.02 \%$ to $0.03 \%$. It can be conclude that $\mathrm{ZnO}$ nanoparticles play an important role in the main properties of polymer composites.

\section{INTRODUCTION}

Currently, around 50\% of packaging products made of a polymer which is mostly generated from fossil fuels. Bio-based polymers can play an important role, unlike conventional plastics that can increase emissions of greenhouse gases (carbon dioxide) [1]. Besides, the production and use of biodegradable polymers can also help decrease the speed of fossil fuels consumption. Since the beginning the concept of chemical macromolecules was introduced, it has been a challenge for polymer scientists to figure out and invent new monomer-to-polymer systems that could form new polymer products accurately, controlling molecular weight and forming more promising material properties [2]. The resulting polymer products can be adapted to the ability of supramolecular induction in

(C) 2020 The Author(s). This is an open access article distributed under the terms of the Creative Commons Attribution License, which permits unrestricted use, distribution, and reproduction in any medium, provided the original author and source are credited. 
aqueous media or interfaces to produce micro or nanostructures with almost unlimited applications in the fields of pharmaceutical, medical and biotechnology.

Polylactic acid (PLA) is an abundant, commercially available, environmental friendly polymer due to its biodegradability and good sitfness properties. Another advantage of the PLA are transparent and safe to use for the medical field. PLA applied usually for beverage bottles, plastic bottles of chemicals, materials chairs, cutlery, plastic bags, car components, shelves, buckets, and others. The latest application of PLA the medical field are used as artificial leather, sewing thread operations, drug capsules and also for tissue engineering because the body can absorb it [3],[4],[5]. PLA can be formed through the esterification process lactic acid obtained by fermentation by bacteria using substrates starches or simple sugars[6]. In addition, the PLA has a lower mechanical and thermal properties compared to other polymers. Therefore, to overcome these weaknesses, PLA can be enhanced properties with the addition of filler material as chitosan, zinc oxide, clay and others in the form of nanocomposite [7].

Chitosan is a chemical compound derived from chitin biological material and organic compound that is abundant in nature after cellulose. Chitin is generally derived from the framework of the group of invertebrate animals Arthopoda sp, sp Mollusk, Coelenterata sp, annelids sp, Nematodes sp, and some of the group of fungi. As the main source is the shell of crustaceans sp, named shrimp, lobster, crab and other shell-bearing animals with chitin content of between 65-70 percent[8],[9]. Because of the characters of chitosan are hydrophobic, high of stability and also has normal PH, the insertion of this inorganic particles to polymer such as PLA has proven to be efficient to improve main properties of polymer composites such as mechanical, thermal and water absorbtion properties [10],[11],[12].

$\mathrm{ZnO}$ (zinc oxide) formed as powder and insoluble in water such an inorganic compound which can be used as an additive for materials such as rubber, plastics, ceramics and others. It has a high capacity and thermal conductivity, and also high melting temperature [13],[14]. ZnO nanoparticles can be formed in various ways such as process LeClaire, Direct Process, Wet Chemical Process, or a method of vapour-liquid-solid. ZnO nanostructures have some morphology, including nanowires, nanorod, tetrapods, and more [15],[16]. Nanoparticles of zinc oxide is a well known inorganic environment-friendly and many researchs had use this because of multifunctional additives which can be regarded as a nanofiller for polymers that give properties such as antibacterial, increased mechanical, thermal and intensive ultraviolet absorption properties [17],[18],[19].

A composite material is a mixture of two or more phases, which are different to produce specific properties and characteristics that cannot be achieved by the single material[20],[21]. Currently, focus of research is how to improve an existing product on the market to be even more reliable than the original product. Polymers are on the fast track of product innovation. Composites have strength, roughness, toughness, heat resistance or a combination of desired properties better when compared to the properties of a single element[22],[23],[24].

The purpose of this study is to produce and investigate nanocomposites PLCHZ (Polylactic acid/Chitosan by adding some concentration of $\mathrm{ZnO}$ nanoparticles) in several variation (PLCHZa, PLCHZb, and PLCHZc). Nanocomposites polymers are formed by dispersing $\mathrm{ZnO}$ nanoparticles into the PLA polymer matrix mixed with chitosan[25]. ZnO nanoparticles as supporting material synthesis are using the method of direct precipitation through direct mixing sol-gel forming solution with the advantage is a simpler and lower cost. As the result, nanocomposites showed an increase in mechanical, thermal stability, and water absorbtion properties without increasing specific gravity and loss of optical properties [26],[27]. Several methods of characterization were performed using Thermogravimetric Analysis (TGA), Mechanical test (tensile, modulus and elongation at break), and water absorbtion test.

\section{MATERIALS AND METHODS}

\subsection{MATERIALS}

All the chemicals used for the formation of $\mathrm{ZnO}$ nanoparticles and composites as are analytical reagents (99.9\% pure), Polylactic Acid (PLA) grade (3001D) derived from Nature Work LLC, USA with a melting point of $190{ }^{\circ} \mathrm{C}$ and $1.24 \mathrm{~g} / \mathrm{cm}$ of specific gravity, zinc acetate dehydrate (CAS. 5970-45-6) supplied from Merck, NaOH pellet (sodium hydroxide) (CAS. 1310-73-2) was obtained from Merck, Ethanol (CAS. 64-17-5) supplied by Sigma-Aldrich, and 
chloroform (CAS. 67-66-3) is used as a solvent, and chitosan C3646 commercial from Sigma-Aldrich as an additional ingredient for fillers and reinforcing.

\subsection{METHOD}

\subsubsection{Preparation of ZnO Nanoparticles}

A total of $0.25 \mathrm{M}$ solution of zinc acetate dihydrate $(\mathrm{Zn}(\mathrm{CH} 3 \mathrm{CO} 2) \cdot 2 \mathrm{H} 2 \mathrm{O})$ was prepared with deionized water by dissolving it. Then $0.8 \mathrm{M}$ of $\mathrm{NaOH}$ was added a few drops into solution of zinc acetate dihydrate with continue stirring at temperature of $25^{\circ} \mathrm{C}$ for about 2 hours [28].The solution was continuously stirred until a white precipitate is formed cause the reaction of $\mathrm{NaOH}$ and zinc acetate dihydrate. Once formed, the precipitate is done then filtered and washed with ethanol and water to remove residual sodium hydroxide. The precipitate then dried for about 24 hours at $50^{\circ} \mathrm{C}$ in the oven, then grinded with PSA tools (nanoPartica SZ-100V2 Series) to form ZnO nanoparticles.

\subsubsection{Preparation of Composites (PLA, PLCH, PLCHZa, PLCHZb and PLCHZc)}

Samples was formed as a composite test sample are divided into five types. Those are PLA, PLCH (Polylactic acid/chitosan), and PLCHZa, PLCHZb, PLCHZc (PLCH and ZnO nanoparticles with different concentrations). Formation of pure PLA is carried out through mixing PLA pellet of 20 grams with $15 \mathrm{wt} \%$ solution of chloroform to form a viscous liquid with the mixing process in a water bath at $60^{\circ} \mathrm{C}$ [29]. Subsequently a solution are casted evenly on Petri dish a thickness of about $0.1 \mathrm{~mm}$ and dried for 24 in order to evaporate the chloroform as solvent. It was followed by the formation of PLCH wherein 20 grams of PLA film mixed with $5 \mathrm{wt} \%$ chitosan by the same method as before using chloroform solvent until all the ingredients are fully soluble, then printed with the same thickness on a baking sheet [30]. Likewise, the variated PLCHZa, PLCHZb, PLCHZc samples ( $2 \mathrm{wt} \%, 3 \mathrm{wt} \%$ and 4 wt $\%$ of $\mathrm{ZnO}$ nanoparticles, respectively) are carried out through the same method as the previous step in the same solvent (choloform), same filler (chitosan) and $\mathrm{ZnO}$ as the support material based on each the samples concentration. The solution was stirred at $60^{\circ} \mathrm{C}$ until the handler to dissolve completely. Then the sample allowed to stand for 24 hours to throw away the solvent and peeled from the mould to doing test in the form of mechanical, thermal resistant, and water absorbtion test.

\subsection{CHARACTERIZATION}

\subsubsection{Mechanical Test}

Tensile properties included strength, modulus and elongation at break solving pure PLA films and composite films mix is determined by using Shimadzu Universal Testing Machine Model E43. It uses set capacity of $10 \mathrm{kN}$, based on ASTM D638. his is carried out under tension mode at a single strain rate of $10 \mathrm{~mm} / \mathrm{min}$ at room temperature and the result is taken as the average of four tests.

\subsubsection{Thermo Gravimetric Analysis (TGA)}

The thermal stability of the samples is determined by means of thermogravimetric analyzer, using a Perkin Elmer thermogravimetric analysis at a heating rate of $10^{\circ} \mathrm{C} / \mathrm{min}$ under nitrogen atmosphere, from $50{ }^{\circ} \mathrm{C}$ to $700{ }^{\circ} \mathrm{C}$. Approximately $2 \mathrm{mg}$ of each sample is analyzed and consequently the weight loss of samples is determined.

\subsubsection{Water Absorption Test}

Water absorption is carried out by preparing a $6 \mathrm{~mm}$ ball-shaped sample according to ASTM D570. Furthermore, the samples were dryed at $60^{\circ} \mathrm{C}$ for 1 hour, then allowed to cool in a desiccator. The sample was weighed immediately after being rotated and immersed in deionized water in room temperature for about 24 hours. After completing it, the sample is transferred in a dry state and weighed. After that, do the same treatment again. Samples 
were prepared to go back into the air and weighed again for ten days. Water absorption is expressed as the increase in weight percent and is calculated according to the formula shown in Equation (1):

Water absorbtion $(\%)=(\mathrm{W} 2-\mathrm{W} 1) / \mathrm{W} 1 \times 100 \%$

\section{RESULTS AND DISCUSSIONS}

\subsection{MECHANICAL PROPERTIES}

Tensile strength, tensile modulus and elongation at break of the PLA, PLCH and PLCHZa, PLCHZb, and PLCHZc composites have been investigated through coaxial force by Universal Testing Machine tools. The variation in the tensile strength, tensile modulus and elongation at break are functions of the optimum dispersion and good intercomponent interaction between the PLA, chitosan and ZnO nanoparticle.

Figure.1 (a) describes the values of tensile strength of each samples. Based on these graphs, it can be seen that the addition of chitosan and $\mathrm{ZnO}$ nanoparticle showed improvement better mechanical properties of the polymer when compared to pure polymer without mixing (PLA). Pure PLA has a tensile strength of $13 \mathrm{MPa}$ and declined after added chitosan. However, the addition of $\mathrm{ZnO}$ nanoparticles has further increased tensile strength as reported in previous studies [30]. PLCHZa with $2 \mathrm{wt} \%$ of $\mathrm{ZnO}$ nanoparticles is the most significant variation value tensile strength of $15 \mathrm{MPa}$ compared with PLCHZb and PLCHZc with a tensile strength of only 11.5 and $12 \mathrm{MPa}$, respectively. The same thing was also found in other studies using $\mathrm{ZnO}$ concentrations of $2 \mathrm{wt} \%$ producing the best mechanical value[31],[32]. This pattern of results tells us that the strong nature of the attraction decreases modulus because the amount of $\mathrm{ZnO}$ that is not ideal in mixed. This state of decrease in tensile strength is due to the formation of intramolecular hydrogen bonds due to the portion of one of the excess materials, so there is a split in the mixed matrix. A similar explanation occurs in the modulus results.
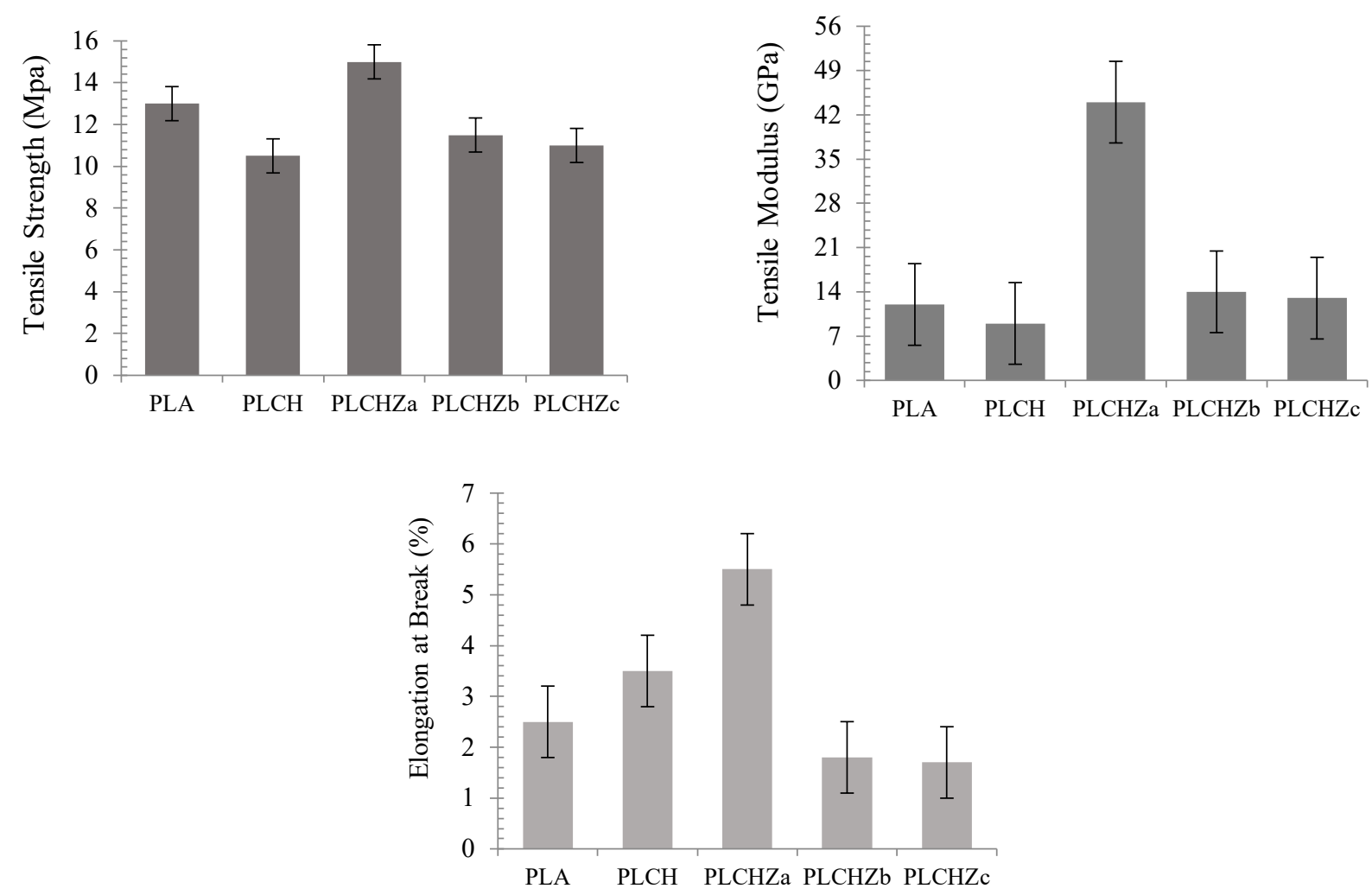

Figure 1: (a) Tensile Strength of various composites, (b) Tensile Modulus of various composites, (c) Elongation At Break of Various Composites 
Based on modulus as shows in Figure. 1 (b), the pattern of results is similar to tensile strength which the PLCH tensile modulus decreased compared to PLA from $12 \mathrm{GPa}$ to $9 \mathrm{GPa}$. It is due to both of chitosan and PLA formed intermolecular hydrogen bond, leading to a composite tensile modulus of PLCH dropped being in formed a phase separation between the two main component [33],[34]. PLCHZa is still the most excellent compositions at $44 \mathrm{MPa}$ modulus value is almost 2 times higher than pure PLA, and higher than other samples PLCHZb and PLCHZc with value of $14 \mathrm{GPa}$ and $13 \mathrm{GPa}$, respectively.

Figure.1 (c) showed elongation at break intensity of the samples. PLA, PLCH and PLCHZa is increased in elongation at break with the addition of chitosan and also $\mathrm{ZnO}$ nanoparticles. Those are almost constant in the composite PLCH of 2.5\% increased and up again in the presence of ZnO nanoparticles in PLCHZa, as reported by[35]. PLCHZa with $2 \mathrm{wt} \% \mathrm{ZnO}$ nanoparticles is the greatest variation breaking extension value of 5.5\%. However, this is not consistent on other samples, which decrease in instensity caused of presence of ZnO nanoparticle in PLCHZb and PLCHZc composites with value of $1,8 \%$ and $1,7 \%$, respectively.

In previous research, uniform dispersion between polymer matrix and filler material which is highly compatible will produce a good interaction which in turn leads to increased mechanical properties and thermal stability of the composite [36]. Improving composite mechanical properties supported by the main controller tensile strength that is the effectiveness of reinforcement properties to facilitate the effective stress transfer at the interface of matrix and filler. In this experiment, $\mathrm{ZnO}$ nanoparticles act as an amplifier nanoscale leading to the strain transfer between matrix and filler. However, the composite tensile strength decreases when the amount of ZnO nanoparticle increased to $3 \mathrm{wt} \%$ and $4 \mathrm{wt} \%$. Similarly to the results of modulus and elongation at break of the weakest in the same sample, caused of the chitosan and PLA contains ring structures. Intermolecular hydrogen bonds was formed by $\mathrm{NH} 3, \mathrm{OH}$, and $\mathrm{C}=\mathrm{O}$, which mainly inhibit the movement of molecular chains. When ZnO nanoparticle incorporated, the hydrogen bonds between molecules weaken and new hydrogen bonds formed between PLA, chitosan and ZnO nanoparticle, making the rotation and movement of the chain molecules more easily, so that its mechanical properties of the composite becomes brittle once doping with excess $\mathrm{ZnO}$ nanoparticles.

\subsection{THERMOGRAVIMETRIC ANALYSIS (TGA)}

Improvement in thermal stability of composites occurred significantly marked by the onset temperature, maximum degradation temperature and percentage of decomposition of various composites, as displayed in Table 1. Temperature degradation test material in this study ranged in the value of $360-380{ }^{\circ} \mathrm{C}$.

Table 1: Data of various composite TGA

\begin{tabular}{|l|l|l|l|}
\hline Samples & Onset Temp $\left({ }^{\circ} \mathrm{C}\right)$ & Max Deg Temp $\left({ }^{\circ} \mathrm{C}\right)$ & \% Decomposition \\
\hline PLA & 290.5 & 367.2 & 90.0 \\
\hline PLCH & 297.7 & 370.5 & 78.0 \\
\hline PLCHZa & 330.6 & 389.7 & 89.8 \\
\hline PLCHZb & 321.9 & 385.6 & 83.0 \\
\hline PLCHZc & 298.4 & 379.9 & 80.9 \\
\hline
\end{tabular}

The onset temperature of pure PLA started at $290.5^{\circ} \mathrm{C}$ with the percentage of decomposition of $90.0 \%$. In one hand, the thermal stability of PLCH composite shown improvement compared to pure PLA as the onset temperature started at $297.7^{\circ} \mathrm{C}$ with the percentage of decomposition of $78 \%$. The presence of $\mathrm{ZnO}$ nanoparticles produces more remarkable effects than in pure PLA or PLCH with increases onset temperature of $330.6^{\circ} \mathrm{C}$ in PLCHZa.

The addition of fillers such as chitosan and ZnO nanoparticles into the PLA matrix gives the effect of increasing the thermal stability of the polymer composite, this behaviour was partially already reported in a previous work [37]. It may be attributed to the formation of bond promoted by the polymer and filler fused stronger, besides acting as efficient protection towards the cracked, provides an effective thermal shielding which make them difficult to separated and degradation become better[38].

Despite the fact that the addition of the fillers brings significant increase in thermal stability, an interesting feature is represented by PLCHZb and PLCHZc with onset temperature of $321,9{ }^{\circ} \mathrm{C}$ and $298.4{ }^{\circ} \mathrm{C}$, respectively. The percentage of decomposition observed of $83 \%$ and $80 \%$, respectively. PLCHZb with the presence of $3 \mathrm{wt} \% \mathrm{ZnO}$ 
nanoparticles losses about $0,03 \%$ of thermal stability compared to PLCHZa, whereas by loading 4 wt $\%$ this loss is shifted to $0,1 \%$ for PLCHZc.

It is important to underline the decreased reached after addition of more over $2 \mathrm{wt} \%$ of $\mathrm{ZnO}$ nanoparticles. The both of composites was not still retains at temperature founded in previous sample tested. Thermal behaviour was reduced due to the excess of fillers which made composites becomes brittle and affects to the thermal stability weaker. It is attributed to a barrier effect of the fillers towards polymer decomposition that not produced ablation, thus decreasing both onset temperature and percentage of decomposition. In general, the better dispersion of the filler in the polymer matrix and the enhancement of the interface between them to form a composite then composites helped provide a high thermal stability.

\subsection{WATER ABSORPTION PROPERTIES}

Water absorption properties of these materials are based on the amount of water is reduced in a trial that has been established over ten days. The pattern of water absorption of the test material is presented in Figure. 2.

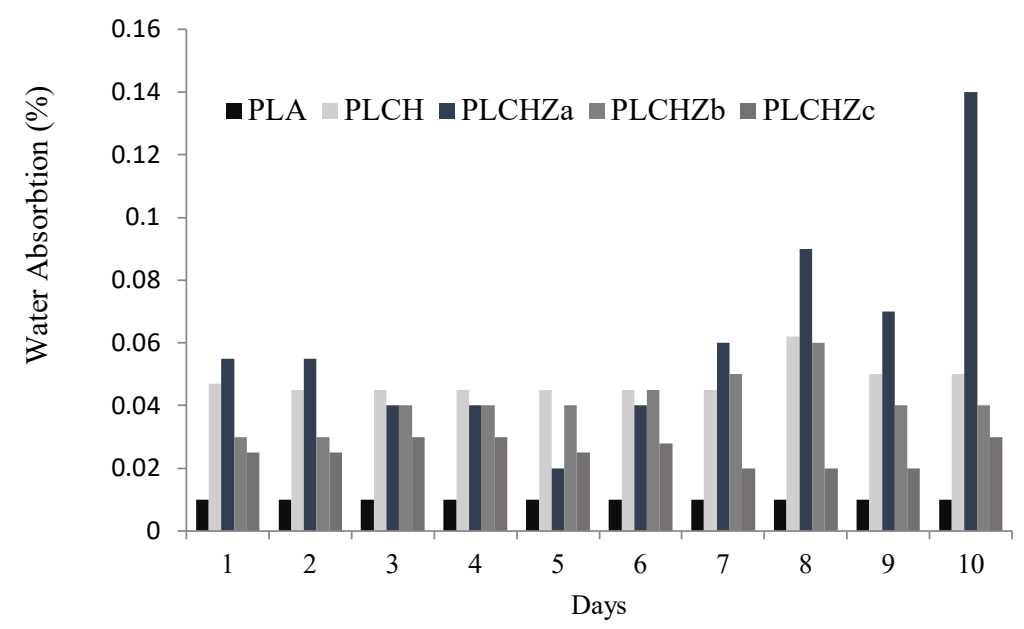

Figure 2: Water Absorption Behaviour of Pure PLA, PLCH, and PLCHZ series Composites (for various ZnO nanoparticles loading)

It was observed that the water absorption rise and fall inconsistently throughout the test as different amount of water is absorbed by the composites tested. It can be observed from Figure.2 pure PLA did not show signs of moisture absorption during the 10 days period, it was confimed that the PLA has hydrophobic properties which sufficiently water resistant showed in value remained constant. However, the different results shown in other sample after blending with chitosan, the water absorption of PLCH composite showed an increased, ranging from $0.045 \%$ to $0.062 \%$, this is due to chitosan highly moisture-sensitive. Similar test results are also reported in other studies that found that PLA composite absorption value reached $0.06 \%$ within two days [40].

The incorporation of ZnO nanoparticles into the PLCHZa, PLCHZb and PLCHZc showed the water absorption of different percentages during the test period. PLCHZc showed the the most lower value of water absorption ranging from $0.02 \%$ to $0.03 \%$. This implied that the incorporation of $4 \mathrm{wt} \% \mathrm{ZnO}$ nanoparticle enhanced the composite with better water barrier property compared with PLCHZa and PLCHZb which higher in water absorption properties. PLCHZa blend composite showed decrement in water absorption content compared to the PLCHZb blend composite with the value ranging from $0.035 \%$ to $0.06 \%$. This implied that the incorporation of 3 wt $\%$ ZnO NPs with PPA enhanced the composite with better water barrier property than PLCHZa. PLCHZa blend composite, Figure 2 showed an even higher decrement in water absorption content ranging from $0.06 \%$ to $0.14 \%$.

Therefore, it can be concluded that PLA/CS/ZnO NPs composites possessed good water barrier properties and the property is more pronounced with higher $\mathrm{ZnO}$ nanoparticles loading, this is also reported in other studies[41],[42]. It can be tailored to the needs and specific applications that will be used. 


\section{CONCLUSIONS AND RECOMMENDATIONS}

Influenced of $\mathrm{ZnO}$ nanoparticles and chitosan on improving the mechanical properties, thermal and water absorption of varoius composites have been investigated. The results showed that chitosan and ZnO plays an important role in increasing the properties of polymer composites. The mechanical and thermal properties increased with the addition of collaboration of chitosan and ZnO particles than pure PLA and PLCH only. This is indicate by samples of PLCHZa as the highest values on tensile strength and tensile modulus of $15 \mathrm{MPa}$ and $44 \mathrm{GPa}$, respectively. In line with the best thermal resistance of the sample is also shown on the PLCHZa with increasing the thermal degradation temperature of $330.6^{\circ} \mathrm{C}$. While other composite samples PLCHZb and PLCHZc experienced a decrease in mechanical and thermal value due to the influence of excess $\mathrm{ZnO}$ components. Meanwhile, the water absorption test found that PLCHZc has better absorption ability than other samples with the lowest percentage absorption rate of $0.02 \%$ to $0.03 \%$ during the test day.

\section{SOURCES OF FUNDING}

This research received no specific grant from any funding agency in the public, commercial, or not-for-profit sectors.

\section{CONFLICT OF INTEREST}

The author have declared that no competing interests exist.

\section{ACKNOWLEDGMENT}

The research work reported in this paper has been funded by the Ministry of Education and Culture of the Republic of Indonesia for the financial support through the grant number 144/ SP2H/ AMD/ LT/ DPRM/ 2020.

\section{REFERENCES}

[1] M. Zameni M.R. Vaezi., "Synthesis of Zinc Oxide Nanostructured Thin Film by Sol- Gel Method and Evaluation of Gas Sensing Properties", International Journal of Engineering-Transactions TRANSACTIONS B: Applications, 27, 2014, 757-762.

[2] H. Heydarzadeh Darzi, S. Gilani, M. Farrokhi, S. M. M. Nouri, G. Karimi., "Textural and Structural Characterizations of Mesoporous Chitosan Beads for Immobilization of Alpha-Amylase: Diffusivity and Sustainability of Biocatalyst", International Journal of Engineering-Transactions TRANSACTIONS B: Applications, 32, 2019, 207-216.

[3] O. Valerio, M. Misra, and A. K. Mohanty., "Statistical design of sustainable thermoplastic blends of poly (glycerol succinate-co-maleate) (PGSMA), poly (lactic acid) (PLA) and poly (butylene succinate) (PBS)". Polyme. Test, 65, 2018, 420-428.

[4] Golestanipour, M., Khadivi, H., Sasani, N. and Sadeghian, M.H., "A novel, simple and cost effective al a356/al2o3 nano-composite manufacturing route with uniform distribution of nanoparticles", International Journal of Engineering-Transactions C: Aspects, 28, 2015, 1320-1327.

[5] S. Mosalman S. Rashahmadi R. Hasanzadeh., "The Effect of TiO2 Nanoparticles on Mechanical Properties of Poly Methyl Methacrylate Nanocomposites", International Journal of Engineering-Transactions TRANSACTIONS B: Applications, 30, 2017, 807-813.

[6] Jamiluddin Jaafar, Januar Parlaungan Siregar, Mohd Bijarimi Mat Piah, Tezara Cionita, Sharmiza Adnan, Teuku Rihayat., "Influence of Selected Treatment on Tensile Properties of Short Pineapple Leaf Fiber Reinforced Tapioca Resin Biopolymer Composites", Journal of Polymers and the Environment, 26, 2018, 4271-4281.

[7] Azadeh Khosravia, Abdolhossein Fereidoona, Mohammad Mehdi Khorasanib Ghasem Naderic Mohammad Reza Ganjali de Payam Zarrintajf Mohammad Reza Saebg Tomy J.Gutiérrezh., "Soft and hard sections from cellulose-reinforced poly(lactic acid)-based food packaging films: A critical review" Food Packaging and Shelf Life, 23, 2020, 1-17. 
Effect of Zinc Oxide Nanoparticles on The Thermal, Mechanical and Water Absorption Properties of Polylactic Acid/Chitosan Composites

[8] L. Midya, A. Shankar, C. Banerjee, A. Baran, and S. Pal., "Novel nanocomposite derived from ZnO/CdS QDs embedded crosslinked chitosan: An efficient photocatalyst and effective antibacterial agent", J. Hazard. Mater, 369, 2019, 398-407.

[9] Teuku Rihayat, M. Saari, M. Hilmi Mahmood, Wan Md Zin Wan Yunus, Suraya Abdul Rashid, K.Z.H.M. Dahlan, S. M. Sapuan., "Mechanical Characterisation of Polyurethane/Clay Nanocomposites", Polymers and Polymer Composites, 15, 2007, 647-652.

[10] E. Bahremandi, S. Karbasi, H. Salehi, and M. Rafienia., "Potential of an electrospun composite scaffold of poly (3-hydroxybutyrate) - chitosan/alumina nanowires in bone tissue engineering applications", Mater. Sci. Eng, 99, 2019, 1075-1091.

[11] S. Y. Purwaningsih, M. Zainuri, T. Triwikantoro, S. Pratapa, D. Darminto., "Structural, Optical and Defect State Analyses of ZnO Nanoparticle Films", International Journal of Engineering-Transactions TRANSACTIONS B: Applications, 33, 2020, 852-860.

[12] P. Taylor, D. Kurniawan, B. S. Kim, H. Y. Lee, J. Y. Lim, D. Kurniawan, B. S. Kim, H. Y. Lee, and J. Y. Lim., "Effect of Silane Treatment on Mechanical Properties of Basalt Fiber / Polylactic Acid Ecofriendly Composites Effect of Silane Treatment on Mechanical Properties of Basalt Fiber / Polylactic Acid Ecofriendly Composites". Polymer-Plastics Technology and Engineering, 1, 2015, 37-41.

[13] Teuku Rihayat, Suryani., "Synthesis and properties of biobased polyurethane/montmorillonite nanocomposites", World Academy of Science, Engineering and Technology, 4, 2010, 714-718.

[14] O. Boura-theodoridou, A. Giannakas, P. Katapodis, H. Stamatis, A. Ladavos, and N. Barkoula., "Performance of $\mathrm{ZnO} /$ chitosan nanocomposite films for antimicrobial packaging applications as a function of $\mathrm{NaOH}$ treatment and glycerol/PVOH blending". Food Packag. Shelf Life, 23, 2020, 1-9.

[15] T Rihayat, S Suryani, T Fauzi, H Agusnar, B Wirjosentono, Syafruddin, Helmi, Zulkifli, P N Alam and M Sami. "Mechanical properties evaluation of single and hybrid composites polyester reinforced bamboo, PALF and coir fiber", IOP Conference Series: Materials Science and Engineering, 334, 2018, 1-8.

[16] Javiera Sepulveda, Carolina Villegas, Alejandra Torresa, Esteban Vargas, Francisco Rodrigueza, Samuel Baltazar, Alejandro Pradad Adrian Rojas, Julio Romero, Simon Faba, María Jose, Galottoa., "Effect of functionalized silica nanoparticles on the mass transfer process in active PLA nanocomposite films obtained by supercritical impregnation for sustainable food packaging", The Journal of Supercritical Fluids, 161, 2020, 104844.

[17] J. F. S. Bombonatti, A. Y. Furuse, V. D. Silva, T. A. Simões, E. S. Medeiros, J. J. Blaker, N. Silikas, and R. F. L. Mondelli. "Improved mechanical performance of self-adhesive resin cement filled with hybrid nanofibersembedded with niobium pentoxide", Dent. Mater, 3418, 2019, 1-14.

[18] M. Heydari-majd, B. Ghanbarzadeh, and M. Shahidi-noghabi. "A new active nanocomposite film based on PLA/ZnO nanoparticle/essential oils for the preservation of refrigerated Otolithes ruber fillets". Food Packaging and Shelf Life, 19, 2019, 94-103.

[19] Teuku Rihayat, Suryani Salim, Halim Zaini, Salmiyah, Cut Aja Rahmawati, Kurniati, Yeni Irawan, Zaimahwati., "Synthesis, characterization and microbial protection of palm oil-based polyurethane / bentonite / chitosan as paint and coating material". ICSREE,.1, 2017, 10-13.

[20] N. K. Chandramohan., "Variation in compressive and flexural strength of the carbon epoxy composites with the addition of various fillers to the epoxy resin", Mater. Today Proc, 6, 2019, 6-10.

[21] Chi-Hui Tsou, Chen Gao, Manuel De Guzman, Dung-Yi Wu, Wei-Song Hung, Lin Yuan, Maw-Chenrng Suen, Jentaut Yeh., "Preparation and characterization of poly (lactic acid) with adipate ester added as a plasticizer", Polymers and Polymer Composites, 26, 2018, 446-453.

[22] A. Akshaykranth, T. V. Rao, and R. R. Kumar., "Growth of ZnO nanorods on biodegradable poly (lactic acid) (PLA) substrates by low temperature solution method", Mater. Lett, 1, 2019, 12-18.

[23] S. Salim, H. Agusnar, B. Wirjosentono, Tamrin, H. Marpaung, T. Rihayat, Nurhanifa, and Adriana., "Synthesis and innovation of PLA/clay nanocomposite characterization againts to mechanical and thermal properties", Mater. Sci. Eng, 334, 2018, 1-7.

[24] B. Wirjosentono, R. Siburian, and T. Rihayat., "Modification of PLA/PCL/Aceh's bentonite nanocomposites as biomedical materials", AIP Conf. Proc, 2049, 2018, 1-6.

[25] Y. Zare and K. Y. Rhee., "Following the morphological and thermal properties of PLA/PEO blends containing carbon nanotubes (CNTs) during hydrolytic degradation", Compos. Part B, 175, 2019, 1-13.

International Journal of Research -GRANTHAALAYAH 
[26] M. Rahman, S. Islam, and G. Shu., " Development of PLA/CS/ZnO nanocomposites and optimization its mechanical, thermal and water absorption properties", Polym. Test, 68, 2018, 302-308.

[27] H. Agusnar, B. Wirjosentono, T. Rihayat, and Z. Salisah., "Synthesis and characterization of poly (lactic acid)/chitosan nanocomposites based on renewable resources as biobased-material", J. Phys. Conf. Series, 953, 2018, 1-7.

[28] H. Agusnar, B. Wirjosentono, and T. Rihayat., "Thermal degradation of Aceh's bentonite reinforced poly lactic acid (PLA) based on renewable resources for packaging application", AIP Conf. Proc, 2049, 2018, 1-5.

[29] Suryani, H. Agusnar, B. Wirjosentono, T. Rihayat, and Nurhanifa., "Improving the quality of biopolymer (poly lactic acid) with the addition of bentonite as filler", Mater. Sci. Eng, 222, 2017, 1-7.

[30] E. Lizundia, M. Cristina, A. Guinault, J. Luis, and S. Domenek., "Impact of ZnO nanoparticle morphology on relaxation and transport properties of PLA nanocomposites", Polym. Test, 75, 2019, 175-184.

[31] D. Ponnamma, J. Cabibihan, M. Rajan, S. S. Pethaiah, K. Deshmukh, J. Prasad, S. K. K. Pasha, M. B. Ahamed, J. Krishnegowda, B. N. Chandrashekar, A. Reddy, and C. Cheng, "Synthesis, optimization and applications of ZnO/polymer nanocomposites", Mater. Sci. Eng. C, 98, 2019, 1210-1240.

[32] X. Wang, Z. Huang, M. Wei, T. Lu, D. Nong, J. Zhao, X. Gao, and L. Teng, "Catalytic effect of nanosized ZnO and TiO2 on thermal degradation of poly (lactic acid) and isoconversional kinetic analysis", Thermochim. Act, 672, $2019,14-24$.

[33] Kamthai, S., \& Magaraphan, R, "Development of an active polylactic acid (PLA) packaging film by adding bleached bagasse carboxymethyl cellulose (CMCB) for mango storage life extension", Packaging Technology and Science,.32, 2019, 103-116.

[34] R. Mansa, C. Huang, A. Quintela, F. Rocha, and C. Detellier., "Preparation and characterization of novel clay/PLA nanocomposites", Appl. Clay Sci, 115, 2015, 87-96.

[35] A. Anžlovar, A. Kržan, and E. Žagar, "Degradation of PLA/ZnO and PHBV/ZnO composites prepared by melt processing", Arab. J. Chem, 7, 2017, 1-20.

[36] Y. Chen, L. Xu, X. Wu, and B. Xu, "Thermochimica Acta the influence of nano ZnO coated by phosphazene/triazine bi-group molecular on the flame retardant property and mechanical property of intumescent flame retardant poly (lactic acid) composites", Thermochim. Acta, 679, 2019, 1-8.

[37] N. Noshirvani, B. Ghanbarzadeh, R. Rezaei, and M. Hashemi, "Novel active packaging based on carboxymethyl cellulose-chitosan-ZnO NPs nanocomposite for increasing the shelf life of bread", Food Packag. Shelf Life, 11, 2017, 106-114.

[38] R. T. De Silva, P. Pasbakhsh, L. Sui, and A. Yoong, "Applied Clay Science ZnO deposited / encapsulated halloysite - poly (lactic acid) (PLA) nanocomposites for high performance packaging films with improved mechanical and antimicrobial properties", Appl. Clay Sci, 111, 2015, 10-20.

[39] Teuku Rihayat, Suryani Salim, Zaimahwati., "Effects of Heat Treatment on the Properties of Polyurethane/Clay Nanocomposites Paint", Applied Mechanics and Materials, 525, 2014, 97-100.

[40] R. C. Nonato, L. H. I. Mei, B. C. Bonse, E. F. Chinaglia, and A. R. Morales, "Nanocomposites of PLA containing ZnO nano fibers made by solvent cast 3D printing: Production and characterization", Eur. Polym. J, 114, 2019, 271278.

[41] C. Yang, R. Han, M. Nie, and Q. Wang, "Interfacial reinforcement mechanism in poly (lactic acid)/ natural fiber biocomposites featuring ZnO nanowires at the interface", Mater. Des, 186, 2020, 1-7.

[42] F. Croisier and C. Jérôme, "Chitosan-based biomaterials for tissue engineering", Eur. Polym. J, 49, 2013, 780792. 